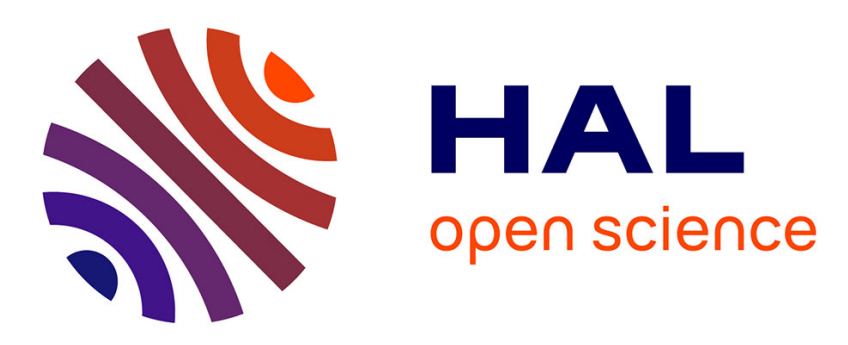

\title{
Lipid phase separation induced by the apolar polyisoprenoid squalane demonstrates its role in membrane domain formation in archaeal membranes
}

Marta Salvador-Castell, Bruno Demé, Phil Oger, Judith Peters

\section{To cite this version:}

Marta Salvador-Castell, Bruno Demé, Phil Oger, Judith Peters. Lipid phase separation induced by the apolar polyisoprenoid squalane demonstrates its role in membrane domain formation in archaeal membranes. Langmuir, inPress, 10.1021/acs.langmuir.0c00901 . hal-02862864

\section{HAL Id: hal-02862864 \\ https://hal.science/hal-02862864}

Submitted on 9 Jun 2020

HAL is a multi-disciplinary open access archive for the deposit and dissemination of scientific research documents, whether they are published or not. The documents may come from teaching and research institutions in France or abroad, or from public or private research centers.
L'archive ouverte pluridisciplinaire $\mathbf{H A L}$, est destinée au dépôt et à la diffusion de documents scientifiques de niveau recherche, publiés ou non, émanant des établissements d'enseignement et de recherche français ou étrangers, des laboratoires publics ou privés. 


\title{
Article
}

\author{
Lipid phase separation induced by the apolar polyisoprenoid squalane \\ demonstrates its role in membrane domain formation in archaeal membranes \\ Marta Salvador-Castell, Bruno Demé, Phil Oger, and Judith Peters \\ Langmuir, Just Accepted Manuscript • DOI: 10.1021/acs.langmuir.0c00901 • Publication Date (Web): 09 Jun 2020
}

Downloaded from pubs.acs.org on June 9, 2020

\section{Just Accepted}

"Just Accepted" manuscripts have been peer-reviewed and accepted for publication. They are posted online prior to technical editing, formatting for publication and author proofing. The American Chemical Society provides "Just Accepted" as a service to the research community to expedite the dissemination of scientific material as soon as possible after acceptance. "Just Accepted" manuscripts appear in full in PDF format accompanied by an HTML abstract. "Just Accepted" manuscripts have been fully peer reviewed, but should not be considered the official version of record. They are citable by the Digital Object Identifier (DOI®). "Just Accepted" is an optional service offered to authors. Therefore, the "Just Accepted" Web site may not include all articles that will be published in the journal. After a manuscript is technically edited and formatted, it will be removed from the "Just Accepted" Web site and published as an ASAP article. Note that technical editing may introduce minor changes to the manuscript text and/or graphics which could affect content, and all legal disclaimers and ethical guidelines that apply to the journal pertain. ACS cannot be held responsible for errors or consequences arising from the use of information contained in these "Just Accepted" manuscripts. 


\title{
Lipid phase separation induced by the apolar
} polyisoprenoid squalane demonstrates its role in membrane domain formation in archaeal membranes

\author{
M. Salvador-Castella, B. Deméb, P. Ogera and J. Peters ${ }^{b, c^{*}}$ \\ a INSA Lyon, Université de Lyon, CNRS, UMR5240, Villeurbanne, France. \\ b Institut Laue Langevin, F-38042 Grenoble Cedex 9, France. \\ c Univ. Grenoble Alpes, CNRS, LIPhy, 38000 Grenoble, France.
}

KEYWORDS Archaea, phospholipids, membrane domains, squalane, neutron

diffraction, lipid phase separation

\begin{abstract}
Archaea synthesize methyl-branched, ether phospholipids, which confer the archaeal membrane exceptional physico-chemical properties. A novel membrane organization has been proposed recently to explain the thermal and high pressure
\end{abstract}


tolerance of the polyextremophilic archaeon Thermococcus barophilus. According to this theoretical model, apolar molecules could populate the midplane of the bilayer and could alter the physico-chemical properties of the membrane, among which the possibility to form membrane domains. We tested this hypothesis using neutron diffraction on a model archaeal membrane composed of two archaeal diether lipids with phosphocholine and phosphoethanolamine headgroups in presence of the apolar polyisoprenoid squalane. We show that squalane is inserted in the midplane at a maximal concentration between 5 and $10 \mathrm{~mol} \%$ and that squalane can modify the lateral organization of the membrane and induces the coexistence of separate phases. The lateral reorganization is temperature- and squalane concentration-dependent and could be due to the release of lipid chain frustration and the induction of a negative curvature in the lipids. 


\section{Introduction}

A cell membrane is a dynamic structure composed of proteins and lipids. ${ }^{1}$ Membrane structural lipids are mainly phospholipids which vary in hydrophobic chain length, level of saturation, branching and type of polar head group and hence, display variable properties.

Despite this great lipid diversity, a cell needs to maintain its membrane functional, i.e. keep the membrane parameters in a very narrow range of values, which include a liquid crystalline phase, specific rigidity and permeabilities. To achieve this, cells have developed the ability to control their membrane lipid compositions as a function of environmental characteristics, which has been coined the name homeoviscous adaptation. ${ }^{2}$ Controlling membrane lipid compositions allows the cell to influence the parameter values of its cell membrane and even provoke the coexistence of different functional lipid bilayer phases. ${ }^{3-7}$ If these lipid phases not only have different bilayer thicknesses, but also have different physico-chemical parameters, such as lipid dynamics or stiffness, they have the ability to create membrane domains of specialized functions. These have been demonstrated in Eukaryotes ${ }^{8-11}$, and in Bacteria ${ }^{12,13}$. Furthermore, several cellular processes, such as membrane fusion and fission or protein insertion in 
the membrane, require specific, membrane curvatures. Since not all lipids induce the same lipid curvature, cells have the ability to control the curvature of specific regions of the cell membrane to allow these essential cell processes ${ }^{14-16}$. The great importance of membrane domains and its presence in Bacteria and Eukaryote suggest that, although never demonstrated before, Archaea should also present domains in their cell membranes. Supporting this view, in Archaea the liquid-liquid phase separation of lipids has been observed in vitro using a tetraether lipid fraction from the thermoacidophile Sulfolobus acidocaldarius. ${ }^{17}$

Archaeal membranes are formed by self-assembling lipids of unique characteristics relying on a sn-glycerol-1-phosphate backbone, an enantiomer of the usual bacterial and eukaryal sn-glycerol-3-phosphate backbone. Besides, and more important from a physical point of view, the hydrophobic core of archaeal lipids is based on isoprenoid units which confer them a methyl-branched structure, very different from the straight acyl chains of bacterial and eukaryal lipids (Figure 1) which are linked to the glycerol moiety by ether bonds instead of the familiar ester ones of bacterial/eukaryal lipids. ${ }^{18-20}$ 


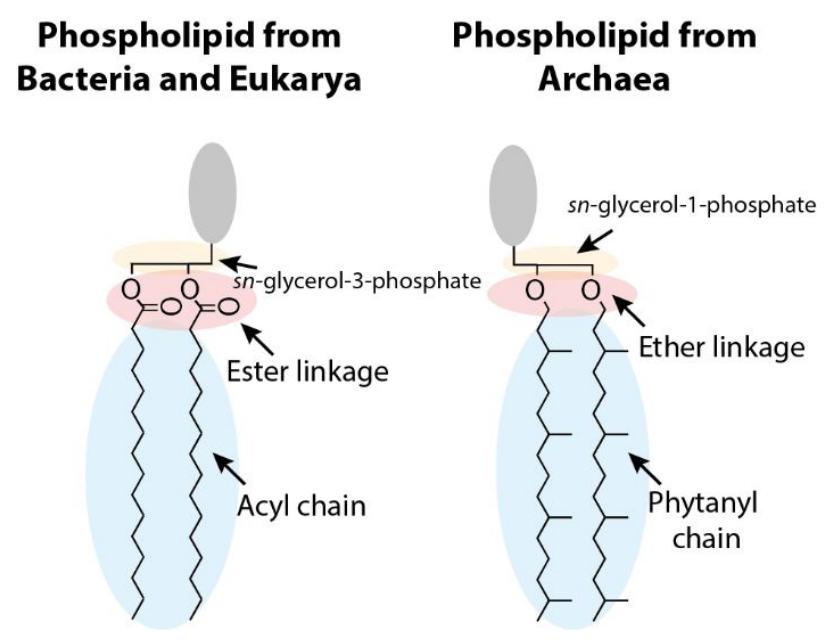

Figure 1. Skeletal representation of phospholipids from Bacteria and Eukarya (left) and from Archaea (right). The arrows indicate the main differences between them.

Most Archaea produce the usual monopolar phospho/glycolipids (diether lipids) which self-assemble into bilayers. In addition, many Archaea also produce bipolar phospho/glycolipids (tetraether lipids) which can form lipid monolayers. 21 The uniqueness of the characteristics of archaeal lipid translate into very different membrane physico-chemical properties. The branched nature of the polyisoprenoid lipid core is largely responsible for the temperature stability ${ }^{22,23}$, the lowered proton permeability ${ }^{24-}$ ${ }^{26}$ and salt tolerance ${ }^{27}$. The ether link is far more stable to oxidation and temperature than the ester link ${ }^{28}$ and allows the phytanoyl lipids to pack more tightly ${ }^{29}$. All these properties 
are further increased in the archaeal monolayer, since the lipid span the entire membrane thickness. ${ }^{20}$ All of which could explain the facility of such microorganisms to live under extreme conditions ${ }^{30}$, such as high temperatures up to $395 \mathrm{~K}^{31}$, low $\mathrm{pH}^{32}$ or high hydrostatic pressures up to $120 \mathrm{MPa}{ }^{33}$.

The presence of bipolar lipids has been specifically associated with the adaptation to HT (high temperature) environments. This view has been challenged since some hyperthermophilic Archaea membranes contain exclusively or a majority of monopolar lipids. For instance, the Archaea growing at the record temperature of $122^{\circ} \mathrm{C}$, M. kandleri, possesses only monopolar lipids. ${ }^{34}$ Furthermore, there is an increasing body of evidence that Archaea from mesophile settings, such as the ocean, can also produce a majority of bipolar, monolayer-forming ether lipids. All these facts lead to question how the lipid bilayer of extremophiles could be stable in such extreme conditions. In 2015, Cario et al. presented a model that could help understand this capability. ${ }^{35}$ In this model, apolar polyisoprenoids, such as squalene and lycopene, are inserted in the lipid membrane. By populating the midplane of the bilayer, apolar polyisoprenoids are proposed to alter membrane functions, especially its rigidity, increasing it, and its permeability, reducing 
water and ions permeation by active blockage of the molecules. Apolar polyisoprenoid concentrations in cells are not well constrained yet. It is known that they vary as a response to homeoviscous adaptation ${ }^{35,36}$ since this observation lead to the formulation of the membrane architecture of Cario and colleagues. It also varies as a function of growth phase. ${ }^{37}$ Due to their capacity to alter membrane physico-chemical parameters, apolar molecules such as squalane may play the role of membrane regulators in Archaea ${ }^{37}$ and change the physicochemical properties of the lipid membrane ${ }^{38}$. We expect that apolar polyisoprenoids such as squalane could play a role on lateral organization of the archaeal membrane, one of the proposed functions of membrane.

Lipid phases have been largely studied by numerous techniques, such as fluorescent methods, atomic force microscopy, molecular dynamic simulations, spin-labelling approaches, such as nuclear magnetic resonance or electron paramagnetic resonance, and scattering procedures, such as neutron reflectivity 39 or neutron diffraction ${ }^{11,40}$. Neutron scattering and particularly, neutron diffraction strengths are based on their nondestructive and highly penetrating nature and on their capability to distinguish hydrogen isotopes, i.e. hydrogen $(H)$ and deuterium $(D)$, by their different neutron cross sections 
41,42. Therefore, the studies based on $H-D$ contrast are numerous ${ }^{43-49}$. All these techniques have provided a lot of information about eukaryal-like lipids: from their rigidity or permeability to the coexistence of domains and their lateral organization. Nevertheless, information about archaeal-like lipids remain elusive. Using neutron diffraction, we have studied a multistack of ordered archaeal lipid bilayers in presence or absence of varying concentrations of hydrogenated and deuterated squalane. We have determined the localization of squalane as a function of concentration and temperature, and have characterized the structural parameter values of each system and its lamellar organization from $298 \mathrm{~K}$ to $358 \mathrm{~K}$. We here demonstrate that squalane induces a lipid phase separation which has the possibility to create membrane domains of specialized functions in archaeal bilayers.

\section{Experimental section}

\section{Chemicals}

1,2-di-O-phytanyl-sn-glycero-3-phosphocholine (DoPhPC) and 1,2-di-O-phytanyl-snglycero-3-phosphoethanolamine (DoPhPE) are both synthetic ether 
glycerophospholipids, bought from Avanti Polar Lipids (Alabaster, USA) in the lyophilized

form and utilized without further purification. Purity guaranteed was $>99 \%$.

2,6,10,15,19,23-Hexamethyltetracosane (squalane) and triacontane were bought from

Sigma - Aldrich Co (Montana, USA).

\section{Sample preparation}

$3 \mathrm{mg}$ of DoPhPC:DoPhPE (9:1 molar) and the correspondent quantity of the apolar molecule in chloroform: methanol $(2: 1)$ were spread on a silicon wafer by the "rock and roll" method and dried overnight under high vacuum ${ }^{50}$. Thereafter, the sample ( $3 \mathrm{mg}$ of lipids on a Si wafer) was hermetically enclosed inside an aluminum sample holder which contained $100 \mu \mathrm{l}$ of water with the corresponding $\mathrm{D}_{2} \mathrm{O}$ percentage. Finally, the sample holder was left at $50 \square \mathrm{C}$ for $48 \mathrm{~h}$ to allow full hydration of lipid bilayers.

\section{Neutron diffraction}

Neutron diffraction experiments were performed on the D16 small momentum transfer diffractometer ${ }^{51}$ at the Institut Laue Langevin (France) using the incident wavelength $\lambda=$ $4.52 \AA$ by a 2omega scan, where omega is the angle between the incident neutron beam 
and the plane of the membrane The detector was fixed during the scan. The accessible q-range was from $0.06 \AA^{-1}$ to $0.51 \AA^{-1}$. The sample holder was placed vertically in a cryostat to precisely control its temperature. The diffraction patterns detected up to fourth order of the Bragg diffraction of the neutrons scattered by the multistack of lipid bilayers. Data treatment was performed by LAMP 52 and OriginPro (OriginPro, Version 2016. OriginLab Corporation, Northampton, MA, USA.). The datasets analyzed for this study can be found at DOI:10.5291/ILL-DATA.8-02-809. ${ }^{54}$ To consider the efficiency of the detector, a calibration file was loaded before any treatment. The calibration file consists in a measurement of $\mathrm{H}_{2} \mathrm{O}$ scattering, making use of the strong isotropic scattering of Hydrogen.. The background was obtained by measuring an empty sample holder twice the amount of time that used for the samples. It was subtracted from sample diffractograms. It was not necessary to correct the data to the beam footprint since the sample was illuminated in the complete omega scan region and therefore, the reflected intensity is constant. The integrated intensities of the Bragg peaks were corrected according to the absorption and analyzed by a Gaussian function as described previously 
55 , which can be used in this case as a suitable model for describing the shape of the reflection. The angle $\theta$ of a Bragg peak is related to the scattering vector q by Eq. (1):

$$
q=\frac{4 \pi \sin (\theta)}{\lambda},
$$

where $\lambda$ is the wavelength. The lamellar $d$-spacing $d$, representing the thickness of the lipid bilayer together with its water layer, was calculated from the q difference between the two first Bragg orders according to Eq. (2):

$$
d=\frac{2 \pi}{q_{2}-q_{1}}
$$

The sum of neutron scattering lengths per unit volume is known as neutron scattering length density (NSLD) profile ${ }^{11,41}$. The NSLD can be calculated as a discrete set of Fourier coefficients $f_{n}$ according to the Eq. (3) ${ }^{56}$ :

$$
\rho_{\text {bilayer }}(z)=\frac{2}{d} \sum_{n=1}^{M} f_{n} v_{n} \cos \left(\frac{2 n \pi}{d} z\right)
$$

where coefficients $\mathrm{f}_{\mathrm{n}}$ can be found due to the formula $I_{n}=\frac{\left|f_{n}\right|^{2}}{Q_{z}}$, here, $\mathrm{Q}_{\mathrm{z}}^{-1}$ is a Lorentz factor which corresponds to the q position of the Bragg peak for oriented bilayers and $I_{n}$ is the integrated intensity of the $n$-th Bragg peak; $d$ is the lamellar spacing of the bilayers in the $z$ direction perpendicular to the lipid bilayer; $z \in\left[\frac{-d}{2} ; \frac{d}{2}\right]$. In order to determine the 


\begin{abstract}
phases of the structure factors, it is possible to use the linear correlation of the structure factor amplitudes and sample $\mathrm{D}_{2} \mathrm{O}$ content ${ }^{57}$. Therefore, each type of sample was measured at three different $\mathrm{D}_{2} \mathrm{O} / \mathrm{H}_{2} \mathrm{O}$ contrasts: $8 \% \mathrm{D}_{2} \mathrm{O}, 50 \% \mathrm{D}_{2} \mathrm{O}$ and $100 \% \mathrm{D}_{2} \mathrm{O}$. To place the data on an absolute scale, the edges of NSLD profile were constraint to the NSLD value of the solvent. 55
\end{abstract}




\section{Results and Discussion}

\section{Localization of squalane in an archaeal bilayer}

The lipids used to model the archaeal membrane were 1,2-di-O-phytanyl-sn-glycero-3-

phosphocholine (DoPhPC) and 1,2-di-O-phytanyl-sn-glycero-3-phosphoethanolamine (DoPhPE) in a ratio of nine to one molar and the addition of varying concentrations of hydrogenated and deuterated squalane: $1 \mathrm{~mol} \%, 2.5 \mathrm{~mol} \%, 5 \mathrm{~mol} \%$ and $10 \mathrm{~mol} \%$. The multilayer nature of the sample causes the emergence of Bragg peaks from which it is easy to directly obtain the membrane repeat distance (d), which includes the thickness of the lipid bilayer and its surrounding water layer. Furthermore, the analysis of Bragg peaks allows to obtain the neutron scattering length density (NSLD) profile which depends on the type and number of atomic nuclei in the membrane depth from the surface normal. For convenience, $0 \AA$ r represents the midplane of the lipid bilayer. It is important to take into consideration that the quality of NSLD profile depends on the number and intensities of diffraction orders. Here, our samples diffracted up to four Bragg peaks (Figure S1). Samples with deuterated (D) squalane present a more intense third order Bragg peak than the samples with hydrogenated $(\mathrm{H})$ squalane (Figure S1). As D isotope has a higher 


\begin{abstract}
scattering length than $\mathrm{H}\left(0.67 \cdot 10^{-12} \mathrm{~cm} \text { and }-0.37 \cdot 10^{-12} \mathrm{~cm} \text {, respectively }\right)^{41}$, the presence
of D-squalane in the lipid bilayer changes Bragg peaks intensities and hence modifies the NSLD profile.
\end{abstract}

The NSLD profile of lipid bilayers presents two characteristic maxima attributable to the glycerol backbone of lipids and a minimum of intensity that corresponds to the methyl terminal groups of the lipid chains. Representative NSLD spectra of samples with $\mathrm{H}$ squalane and D-squalane are presented in Figure 2. The NSLD spectra overlap except for the region from $-10 \AA$ to $10 \AA$, which corresponds to the midplane of the bilayer. In this bilayer depth, samples with D-squalane present an increases intensity due to the higher neutron scattering length of $D$ in comparison to $H$. This $H-D$ neutron scattering length difference allowed to locate squalane in the midplane of the lipid bilayer, in parallel to the membrane surface plane (Figure 2). The same localization is observed for all the studied $\mathrm{H}-\mathrm{D}$ pairs, up to at least $10 \mathrm{~mol} \%$ squalane, which is the highest concentration used in the present study. These results are in line with previous results published by Hauß and colleagues where they have located squalane in a lipid bilayer midplane composed by unsaturated bacteria-like lipids. ${ }^{44}$ However, due to differences in methodologies and 
lipids used, it was necessary to precisely determine the position of squalane in our system.

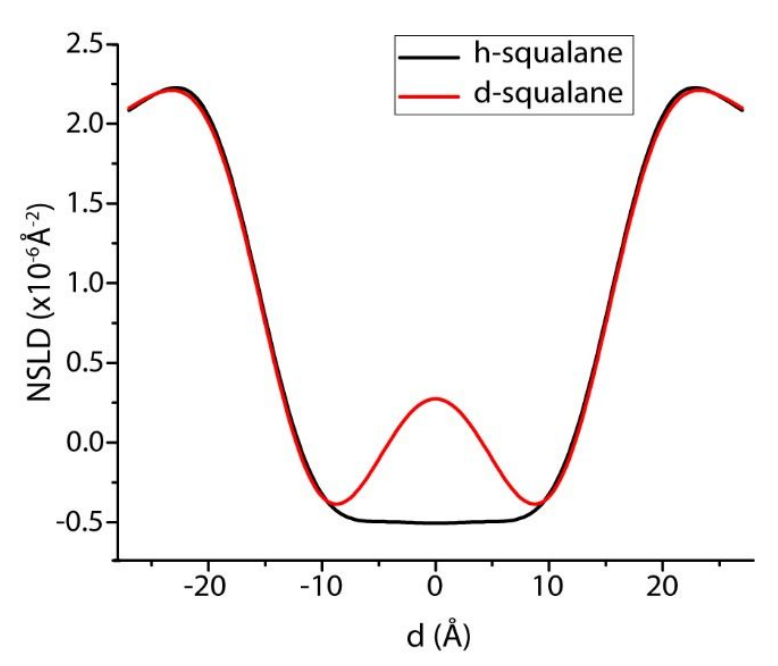

Figure 2. Neutron scattering length density profile of DoPhPC : DoPhPE $(9: 1)+5 \%$ hydrogenated (black) and deuterated squalane (red). The contrast is $50 \% \mathrm{D}_{2} \mathrm{O}$.

From NSLD profiles, we could extract several structural parameters of the lipid bilayer 58: the lipid bilayer thickness $\left(d_{B}\right)$, the thickness of the bilayer hydrocarbon core $\left(2 d_{C}\right)$ and the thickness of the water layers between lipid bilayers $\left(d_{w}\right)($ Table 1$)$. It is observed that the presence of just $1 \mathrm{~mol} \%$ squalane induces an increase of the hydrophobic core thickness of the lipid bilayer by populating its midplane $(32.2 \pm 0.2 \AA$ and $35.0 \pm 0.2$, 
respectively). This behaviour is confirmed up to $10 \mathrm{~mol} \%$ of squalane added into the system.

We could observe that bilayer thickness (Table 1) linearly increases as a function of squalane concentration in the lipid bilayer up to 5 mol\% (e.g. from $51.0 \pm 0.1 \AA$ in absence to $56.6 \pm 0.1 \AA$ in presence of $5 \mathrm{~mol} \%$ squalane) due to the increase of the hydrophobic core thickness (e.g. from $32.2 \pm 0.2 \AA$ in absence to $39.2 \pm 0.2 \AA$ in presence of 5 mol\% squalane). However, this trend is no longer valid at $10 \mathrm{~mol} \%$ squalane. We hypothesized that the lipid bilayer reaches squalane saturation between $5 \mathrm{~mol} \%$ and $10 \mathrm{~mol} \%$, and that therefore, at $10 \mathrm{~mol} \%$, not all squalane may be inserted in the lipid bilayer. Since there was not a different lipid partition, nor a macromolecular phase separation, we believe that at this highest squalane concentration there may be a squalane aggregation not directly visible. This is congruent with the observation that the maximum concentration of squalene inserted in a bacterial-type bilayer composed of 1,2-dioleoyl-sn-glycero-3phosphoethanolamine bilayer is ca. $5 \mathrm{~mol} \%{ }^{59}$. However, it is also possible that squalane gets differentially partitioned between the different phases. 
Table 1. Structural parameters of the lipid bilayer in absence (DoPhPC: DoPhPE (9:1)) and in presence of different percentages of squalane measured at full hydration of 8 $\% \mathrm{D}_{2} \mathrm{O}$ and $298 \mathrm{~K}$.

\begin{tabular}{|l|l|l|l|l|l|}
\hline$\AA$ & $\begin{array}{l}\text { DoPhPC : DoPhPE } \\
(9: 1)\end{array}$ & $\begin{array}{l}1 \mathrm{~mol} \% \\
\text { squalane }\end{array}$ & $\begin{array}{l}+2.5 \mathrm{~mol} \% \\
\text { squalane }\end{array}$ & $\begin{array}{l}5 \mathrm{~mol} \% \\
\text { squalane }\end{array}$ & $\begin{array}{l}+10 \mathrm{~mol} \% \\
\text { squalane }\end{array}$ \\
\hline $\mathrm{d}$ & $51.0 \pm 0.1$ & $52.8 \pm 0.1$ & $53.7 \pm 0.1$ & $56.6 \pm 0.1$ & $54.5 \pm 0.2$ \\
\hline $\mathrm{d}_{\mathrm{B}}$ & $38.4 \pm 0.1$ & $41.8 \pm 0.1$ & $43.0 \pm 0.1$ & $46.8 \pm 0.1$ & $44.1 \pm 0.3$ \\
\hline $2 \mathrm{~d}_{\mathrm{c}}$ & $32.2 \pm 0.2$ & $35.0 \pm 0.2$ & $36.3 \pm 0.2$ & $39.2 \pm 0.2$ & $36.9 \pm 0.5$ \\
\hline $\mathrm{d}_{\mathrm{w}}$ & $12.6 \pm 0.1$ & $11.1 \pm 0.1$ & $10.7 \pm 0.1$ & $9.8 \pm 0.1$ & $10.5 \pm 0.2$ \\
\hline
\end{tabular}

Although here we demonstrated that squalane is localized in the midplane of the archaeal lipid bilayer, such position cannot be extrapolated for all apolar molecules. Indeed, triacontane, a non-branched apolar molecule with the same chemical formula as squalane, is excluded from the bilayer midplane of DoPhPC:DoPhPE as can be seen from the absence of a signal for the deuterated molecule in the NSLD profiles (Figure S2). The exclusion of long alkanes has been reported previously for bacterial and archaeal lipid bilayers. Mclntosh et al. have proposed that triacontane is not placed 
perpendicular to acyl chains and that only smaller non-branched apolar molecules, such as hexane and octane, can be inserted into the bilayer midplane. ${ }^{60}$ Thus, it seems that the methyl-branched structure is also essential for the insertion of a long apolar molecule in the bilayer midplane in the case of archaeal lipids. Squalane and triacontane differ principally by their intrinsic molecular disorder and flexibility. Thus, we hypothesize that triacontane may be too flexible to be stably inserted in the bilayer.

\section{Effect of temperature on the lateral organization of an archaeal model membrane in the}

\section{presence of squalane}

Temperature scans from $298 \mathrm{~K}$ to $358 \mathrm{~K}$ revealed the appearance of a new lipid phase at high temperatures $\left(\mathrm{Ph}_{\mathrm{HT}}\right)$ (Figure 3). The first order Bragg peak for this new phase appears at lower q values, which implies that the phase has a higher d-spacing than the phase present at low temperatures $\left(\mathrm{Ph}_{\mathrm{LT}}\right)$ (Table 2 and 3$)$. For instance, at $358 \mathrm{~K}$ and in absence of squalane, $\mathrm{Ph}_{\mathrm{HT}}$, which is found exclusively at high temperatures, and $\mathrm{Ph}_{\mathrm{LT}}$, which is present at lower temperatures, have a lamellar repeat distance of $62.9 \pm 0.4 \AA$ 
and $54.4 \pm 0.4 \AA$, respectively. In absence or at 1 mol\% squalane, such phase separation was visible at $343 \mathrm{~K}$. High temperatures provoke undulations in the lipid bilayers due to thermal energy, thereby diminishing the line tension between the domain boundaries. ${ }^{61}$ In our case, there exists an unusual phase separation at higher temperatures. It has been demonstrated that the ester analogue of DoPhPC, diphytanoyl phosphatidylcholine, presents a transition on headgroup orientation and a lamellar to non-lamellar phase transition at high temperatures. ${ }^{62,63}$ However in this study, all the observed phases are lamellar phases and the phase separation may be explained by the presence of DoPhPE. As demonstrated for ester-like PE lipids, this phospholipid has a low packing parameter that can cause negative curvatures and non-lamellar phases. Therefore, high temperatures provoke a curvature difference between DoPhPC and DoPhPE inducing a phase separation. The increased line tension would allow the thermodynamically stable coexistence of two phases that otherwise might be a mixture. 

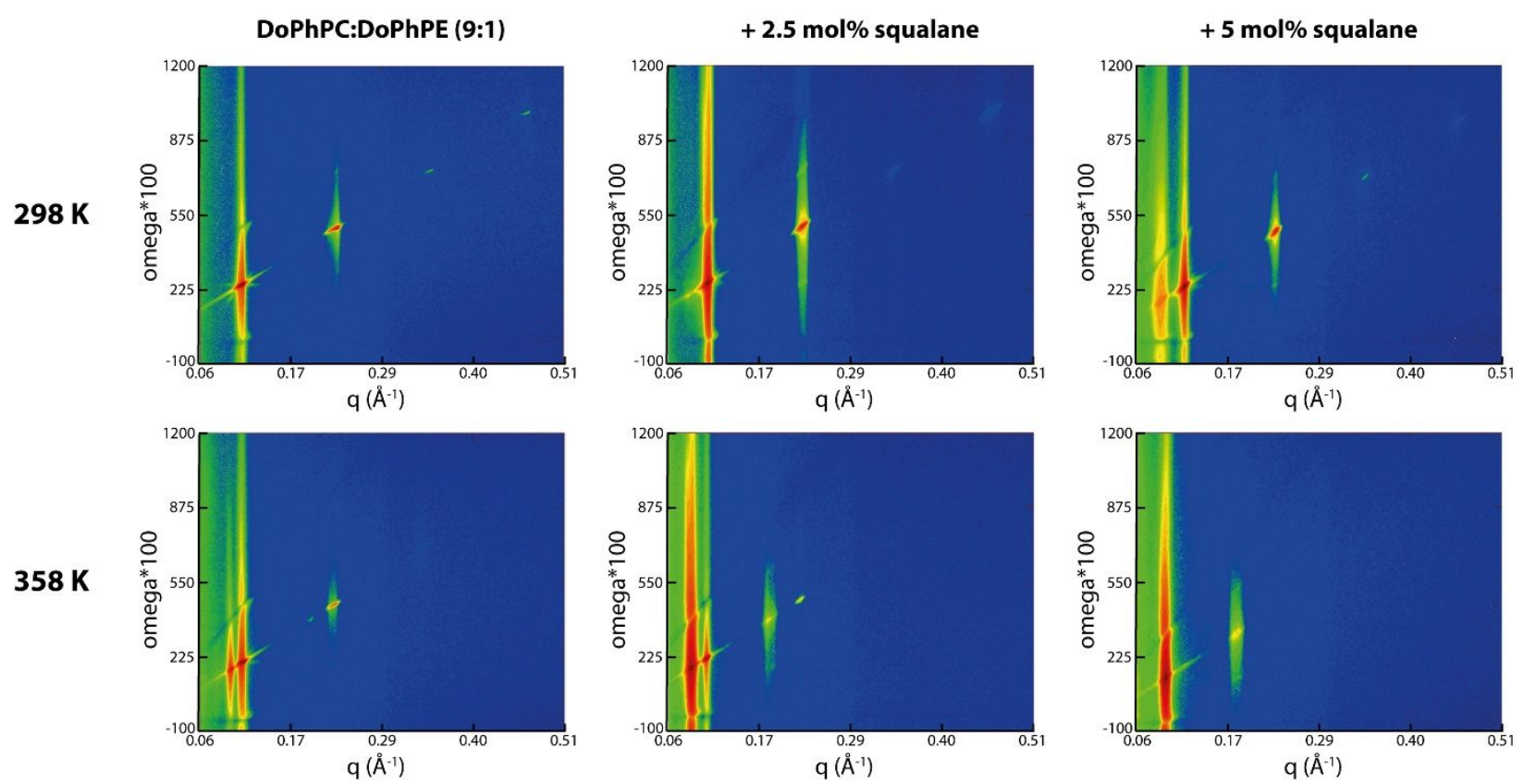

Figure 3. 2D neutron diffractograms of DoPhPC:DoPhPE (9:1) bilayer in absence of squalane and containing $2.5 \mathrm{~mol} \%$ (left) and $5 \mathrm{~mol} \%$ (right) squalane at $298 \mathrm{~K}$ (above) and $358 \mathrm{~K}$ (bottom). The samples were hydrated with $100 \% \mathrm{D}_{2} \mathrm{O}$. We can clearly see how a new phase is induced by high temperature and high percentages of squalane and how at $358 \mathrm{~K}$, for the sample with the highest content of squalane, the new phase is the unique.

Table 2. Lamellar d-spacing of the lipid bilayer $\mathrm{Ph}_{\mathrm{LT}}$ in absence (DoPhPC: DoPhPE (9:1)) and in presence of different percentages of squalane measured under different temperatures at $100 \% \mathrm{D}_{2} \mathrm{O}$. 


\begin{tabular}{|c|c|c|c|c|c|}
\hline$P h_{L T}$ & $298 \mathrm{~K}$ & $313 \mathrm{~K}$ & $328 \mathrm{~K}$ & $343 \mathrm{~K}$ & $358 \mathrm{~K}$ \\
\hline $\begin{array}{l}\text { DoPhPC:DoPhPE } \\
(9: 1)\end{array}$ & $\begin{array}{l}52.6 \\
\AA\end{array}$ & $53.0 \AA$ & $\begin{array}{l}53.1 \\
\AA\end{array}$ & $\begin{array}{l}53.0 \\
\AA\end{array}$ & $54.4 \AA$ \\
\hline + $1 \mathrm{~mol} \%$ squalane & $\begin{array}{l}55.3 \\
\AA\end{array}$ & $55.4 \AA$ & $\begin{array}{l}55.2 \\
\AA\end{array}$ & $\begin{array}{l}54.5 \\
\AA\end{array}$ & $55.1 \AA$ \\
\hline $\begin{array}{l}+\quad 2.5 \quad \mathrm{~mol} \% \\
\text { squalane }\end{array}$ & $\begin{array}{l}52.8 \\
\AA\end{array}$ & $53.0 \AA$ & $\begin{array}{l}52.8 \\
\AA\end{array}$ & $\begin{array}{l}52.8 \\
\AA\end{array}$ & $53.2 \AA$ \\
\hline + 5 mol\% squalane & $\begin{array}{l}54.2 \\
\AA\end{array}$ & $54.2 \AA$ & $\begin{array}{l}54.2 \\
\AA\end{array}$ & $\begin{array}{l}54.3 \\
\AA\end{array}$ & N.P. \\
\hline $\begin{array}{lrl}+ & 10 & \mathrm{~mol} \% \\
\text { squalane } & \end{array}$ & $\begin{array}{l}53.7 \\
\AA\end{array}$ & $54.6 \AA$ & $\begin{array}{l}54.9 \\
\AA\end{array}$ & $\begin{array}{l}55.8 \\
\AA\end{array}$ & N.P. \\
\hline
\end{tabular}

The standard deviation is \pm 0.4 Å. N.P.: not present.

Table 3. Lamellar d-spacing of the lipid bilayer $\mathrm{Ph}_{\mathrm{HT}}$ in absence (DoPhPC: DoPhPE (9:1)) and in presence of different percentages of squalane measured under different temperatures at $100 \% \mathrm{D}_{2} \mathrm{O}$.

\begin{tabular}{|l|l|l|l|l|l|}
\hline $\mathrm{Ph}_{\mathrm{HT}}$ & $298 \mathrm{~K}$ & $313 \mathrm{~K}$ & $328 \mathrm{~K}$ & $343 \mathrm{~K}$ & $358 \mathrm{~K}$ \\
\hline $\begin{array}{l}\text { DoPhPC:DoPhPE } \\
(9: 1)\end{array}$ & N.P. & N.P. & N.P. & $64.0 \AA$ & $62.9 \AA$ \\
\hline+1 mol\% squalane & N.P. & N.P. & N.P. & $80.3 \AA$ & $73.5 \AA$ \\
\hline $\begin{array}{l}\text { squalane } \\
\text { squ mol\% }\end{array}$ & $74.1 \AA$ & $73.0 \AA$ & $72.5 \AA$ & $67.5 \AA$ & $65.3 \AA$ \\
\hline
\end{tabular}




\begin{tabular}{|l|l|l|l|l|l|l|l|l|l|l|}
\hline+5 mol\% squalane & $\begin{array}{l}80.4 \\
\AA\end{array}$ & $\begin{array}{l}70.6 \\
\AA\end{array}$ & $\begin{array}{l}77.9 \\
\AA\end{array}$ & $\begin{array}{l}71.7 \\
\AA\end{array}$ & $\begin{array}{l}76.9 \\
\AA\end{array}$ & $\begin{array}{l}71.3 \\
\AA\end{array}$ & $\begin{array}{l}73.6 \\
\AA\end{array}$ & $\begin{array}{l}69.7 \\
\AA\end{array}$ & $\begin{array}{l}73.6 \\
\AA\end{array}$ & $\begin{array}{l}74.1 \\
\AA\end{array}$ \\
\hline + 10 mol\% squalane & $51.2 \AA$ & $52.2 \AA$ & $60.9 \AA$ & $63.0 \AA$ & $66.5 \AA$ \\
\hline
\end{tabular}

N.P.: not present; N.D.: not determined. The standard deviation is $\pm 0.5 \AA$.

Phase $\mathrm{Ph}_{\mathrm{HT}}$ also appeared in presence of higher concentrations of the apolar molecule

in the system at the lowest temperature tested, e.g. $298 \mathrm{~K}$ (Figure 3). The appearance of the $\mathrm{Ph}_{\mathrm{HT}}$ phase at low temperature when adding squalane implies that the apolar molecule destabilizes the $\mathrm{Ph}_{\mathrm{LT}}$ phase and favors $\mathrm{Ph}_{\mathrm{HT}}$. Squalane was shown previously to reduce lipid packing frustration and to increase negative lipid curvatures ${ }^{64}$. The results presented here suggest that by populating the midplane by squalane could also increase the line tension between both phases in a stabilizing manner that allows their coexistence even at low temperatures.

$\mathrm{Ph}_{H T}$ is broader than $\mathrm{Ph}_{\mathrm{LT}}$, which indicates a reduced capability to organize as multistacks of lipid bilayers. Indeed, for 5 mol\% squalane, the Bragg peaks from $\mathrm{Ph}_{H T}$ can be fitted by two gaussians (Figure S3) and therefore two different $\mathrm{Ph}_{\mathrm{HT}}$ lamellar phases can be extracted (Table 3 ). This is a hint for inhomogeneities in the phase and two 
different membrane repeat distances. Two lamellar phases that coexist form a continuous columnar arrangement across hundreds of lipid bilayers. ${ }^{65}$ The presence of stacked domains causes an increase of the thickness and the diameter of the phase slightly with the number of stacked bilayers, which can explain the broad $\mathrm{Ph}_{\mathrm{HT}}$ peaks (Figure 3).

The presence of squalane in the lipid bilayer causes very particular diffraction patterns as shown in Figure 4 (left). Such diffraction pattern is present at different squalane concentrations, e.g. 2.5, 5 and $10 \mathrm{~mol} \%$ and different temperatures, e.g.: $328 \mathrm{~K}, 343 \mathrm{~K}$ and at $298 \mathrm{~K}$ after cooling from $358 \mathrm{~K}$. In every case, the coexistence of the two $\mathrm{Ph}_{\mathrm{LT}}$ and $\mathrm{Ph}_{\mathrm{HT}}$ phases is observed. The diffraction pattern reveals Bragg peaks up to two diffraction orders out of the $q_{z}$ plane. These diffraction signals are in the $q_{x}$ plane and indicate a highly repeated structure through this plane. From these two Bragg peaks, it was possible to extract the repeat spacing in the $x$-plane $\left(d_{x}\right)$ (Figure 4 (right)), which depends on the concentration of squalane and on the temperature (Table 4). For instance, at $10 \mathrm{~mol} \%$ squalane, we observed a repeat distance of $470 \pm 20 \AA$, which could correspond to the size of the membrane domain. We could link this diffraction to the first order of $\mathrm{Ph}_{\mathrm{LT}}$ at an angle $\theta \sim 10 \square$. We propose that the $\theta$ angle is due to the tilting of $\mathrm{Ph}_{\mathrm{LT}}$, since it has 
already been observed that domains may tilt by an angle depending on their elastic properties and size. ${ }^{66}$ This organization in the $q_{x}$ plane is highly stable since it could be observed $48 \mathrm{~h}$ after the temperature scans while maintaining the membrane at $298 \mathrm{~K}$. Lipid organization on $\mathrm{q}_{\mathrm{x}}$ axis has been frequently observed in ripple phases, a lipid phase that appears between gel and fluid lipid phases, which is characterized by undulations of the lipid bilayer. ${ }^{67-70}$ Nevertheless, this type of organization presents a constant $d-$ spacing and is not due to the coexistence of two phases as illustrated here.
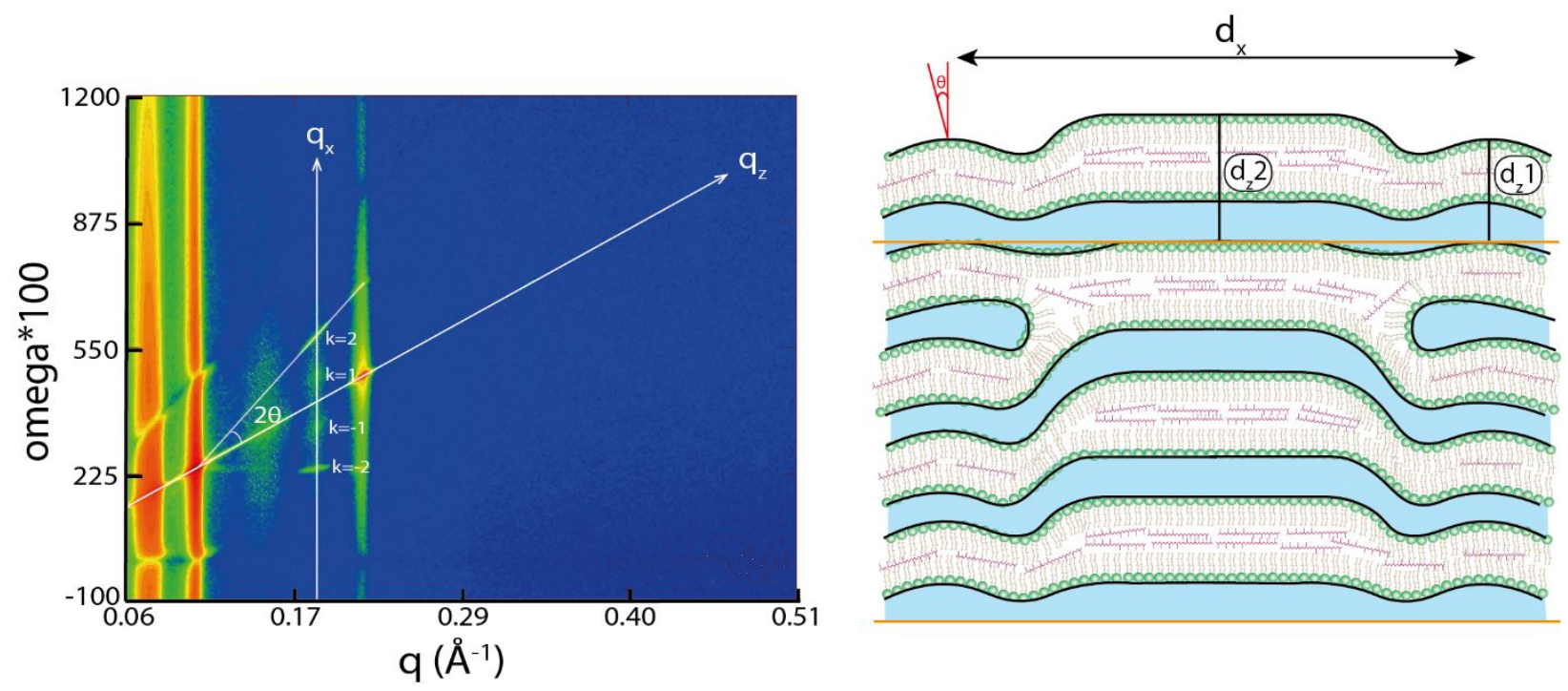

Figure 4. (Left) 2D neutron diffractogram patterns of DoPhPC:DoPhPE (9:1) + 10 mol\% squalane at $328 \mathrm{~K}$. It shows diffraction peaks on two different planes. (Right) Schematic 
representation of the $2 \mathrm{D}$ diffraction patterns from $\mathrm{A}$. There is a coexistence of two lipid phases on the $q_{z}$ plane $\left(d_{z} 1\right.$ and $\left.d_{z} 2\right)$, one of them tilted by an angle $\theta$ and separated by a $d_{x}$ distance. Lipid headgroups are represented in green, lipid phytanyl chains in brown and squalane molecules in magenta, water regions are represented in blue. The two lines in orange defines an organization that would be repeated along $d_{z}$.

Table 4. Distance of the repeated structure along the qz axis in absence (DoPhPC: DoPhPE (9:1)) and in presence of different percentages of squalane measured under different temperatures at $100 \% \mathrm{D}_{2} \mathrm{O}$.

\begin{tabular}{|l|l|l|l|l|l|}
\hline$d_{x}$ & $\begin{array}{l}298 \\
K\end{array}$ & $\begin{array}{l}313 \\
K\end{array}$ & $\begin{array}{l}328 \\
K\end{array}$ & $\begin{array}{l}343 \\
K\end{array}$ & $\begin{array}{l}358 \\
K\end{array}$ \\
\hline $\begin{array}{l}\text { DoPhPC:DoPhPE } \\
(9: 1)\end{array}$ & N.P. & N.P. & N.P. & N.P. & N.P. \\
\hline+1 mol\% squalane & N.P. & N.P. & N.P. & N.P. & N.P. \\
\hline+2.5 mol\% squalane & N.P. & N.P. & $\begin{array}{l}250 \\
\AA\end{array}$ & $\begin{array}{l}475 \\
\AA\end{array}$ & N.P. \\
\hline+5 mol\% squalane & N.P. & $\begin{array}{l}520 \\
\AA\end{array}$ & $\begin{array}{l}520 \\
\AA\end{array}$ & N.P. & N.P. \\
\hline
\end{tabular}




\begin{tabular}{|l|l|l|l|l|l|}
\hline+10 mol\% squalane & N.P. & N.P. & $\begin{array}{l}470 \\
\AA\end{array}$ & $\begin{array}{l}470 \\
\AA\end{array}$ & N.P. \\
& & & & \\
\hline
\end{tabular}

N.P.: not present. The standard error is $\pm 20 \AA$.

We propose that the new $\mathrm{Ph}_{\mathrm{HT}}$ phase is due to the presence of compounds of different curvature. Indeed, there is the difference in headgroup between DoPhPC and DoPhPE. DoPhPE has a small headgroup $\left(-\mathrm{NH}_{3}\right)$ which confers this phospholipid a conical shape, which thus tends to adopt a negative curvature, i.e. the lipid headgroups are tighter packed than the hydrophobic core. ${ }^{15,16,71}$ Such lipid negative curvatures are favored by high temperatures. ${ }^{72}$ In contrast, DoPhPC has a larger polar headgroup $\left(-\mathrm{N}\left(\mathrm{CH}_{3}\right)_{3}\right)$, and a zero curvature. When temperature increases, the system eventually reaches a critical temperature at which the curvature from both lipids are so different that they become incompatible and segregate leading to the observed phase separation at $343 \mathrm{~K}$ in absence of squalane (DoPhPC:DoPhPE, 9:1). It has recently been demonstrated that squalane has a tremendous capability to modulate membrane bending and to induce negative curvature to the DoPhPC:DoPhPE mixture by reducing the lipid chain frustration. ${ }^{64}$ By doing so, the volume occupied by the hydrophobic core of the lipid increases, and the lipid harbors a conical shape, which has a negative curvature, rather than its usual cylindrical one, which has a zero curvature. Here we observe that the curvature of the DoPhPC:DoPhPE mixture tends to become more negative with increasing temperature. In presence of squalane, phase separation could appear at much lower temperatures due to the squalane-induced increased negative curvature. Although the effect of squalane is directly related to the nature of the phospholipids used in the present study, these results suggest that squalane could have the capability to laterally organize the lipid bilayer. Since the lateral organization provided by collective aggregation of lipids is essential for cell 
membranes, squalane may play an essential role for membrane and cellular function. Indeed, the presence of membrane lipid composition heterogeneities leads to divergent physicochemical parameter values in the lipid bilayer, which can translate into functional heterogeneities of the membrane. ${ }^{73}$ For instance, a membrane domain may present a higher affinity to a protein and another highly curved domain may be essential for cell's fission and fusion. ${ }^{74}$

\section{Conclusions}

The use of neutron diffraction and H-D contrast demonstrated that the methyl-branched apolar molecule squalane is located in the midplane of the lipid bilayer, parallel to its membrane surface at concentrations from $1 \mathrm{~mol} \%$ to $10 \mathrm{~mol} \%$, which would ease control their impact on cell membrane, such as on lateral organization. Squalane saturation for a bilayer composed of archaeal lipids with a phosphatidylcholine and a phosphatidylethanolamine polar headgroups has been determined to be between 5 and $10 \mathrm{~mol} \%$. This indicates that this novel membrane architecture, originally presented for $T$. barophilus 35 which produce ca. 1 mol\% squalane, could also apply the bilayer membranes of other members of the archaeal domain, including Archaea producing high quantities of polyisoprenoids, such as alkaliphiles. Further work on the impact of the 


\begin{abstract}
nature of polar headgroups and the ability of a bilayer to accept apolar polisoprenoids would be required to determine the limiting quantities and their impact on membrane parameter values.
\end{abstract}

We have demonstrated that squalane promoted lipid phase separation and a specific and unique lateral organization. Such essential characteristic is polyisoprenoid concentration dependent. It means that Archaea could easily control the lateral heterogeneity of their cell membrane by adjusting the membrane level of apolar polyisoprenoids. Hence, as already demonstrated in Thermococcus barophilus, these apolar molecules could play a central role in the membrane homeoviscous adaptation in Archaea, but also as a membrane regulator to adapt the physiology of membrane domains. For example, the quantity of polyisoprenoids could govern the formation of membrane domains with specialized functions, depending on environmental conditions and cell needs. 


\section{ASSOCIATED CONTENT}

Figure S1. Intensity (a.u.) vs q plot of DoPhPC:DoPhPE (9:1) in absence and in presence of hydrogenated (left) and deuterated squalane under $8 \% \mathrm{D}_{2} \mathrm{O}$ of contrast and $298 \mathrm{~K}$.

Figure S2. Neutron scattering length density profile of DoPhPC:DoPhPE (9:1) and 5 mol\% hydrogenated (black) and deuterated (red) triacontane at $298 \mathrm{~K}$, complete humidity at $8 \% \mathrm{D}_{2} \mathrm{O}$.

Figure S3. Intensity vs q plot of neutron diffraction from DoPhPC:DoPhPE (9:1) with 5 mol\% squalane at $328 \mathrm{~K}$. The region from the first Bragg peak is zoom in and it is fitted (red curve) with two Gaussians (green curves).

\section{AUTHOR INFORMATION}

Corresponding Authors

jpeters@ill.fr 


\section{philippe.oger@insa-lyon.fr}

\section{Author Contributions}

The manuscript was written through contributions of all authors. All authors have given approval to the final version of the manuscript. MS, JP and PO authors convinced and designed the experiment. All authors performed the experiment. MS analyzed the data. All authors discussed the results. MS, JP and PO wrote the manuscript in consultation with BD.

\section{Funding Sources}

This work was supported by the French National Research Agency programme ANR 17-CE11-0012-01 to PO and JP. MS was supported by a PhD grant from the French Ministry of Research.

\section{ACKNOWLEDGMENT}


The authors thank the Institut Laue Langevin for the allocation of beamtime (DOI: 10.5291/ILL-DATA.8-02-809).

\section{REFERENCES}

(1) Goñi, F. M. The Basic Structure and Dynamics of Cell Membranes: An Update of the Singer-Nicolson Model. Biochim. Biophys. Acta - Biomembr. 2014, 1838 (6), 1467-1476. https://doi.org/10.1016/j.bbamem.2014.01.006.

(2) Sinensky, M. Homeoviscous Adaptation-A Homeostatic Process That Regulates the Viscosity of Membrane Lipids in Escherichia Coli. Proc. Natl. Acad. Sci. 1974, 71 (2), 522-525. https://doi.org/10.1073/pnas.71.2.522.

(3) Bagatolli, L. A.; Ipsen, J. H.; Simonsen, A. C.; Mouritsen, O. G. An Outlook on Organization of Lipids in Membranes: Searching for a Realistic Connection with the Organization of Biological Membranes. Prog. Lipid Res. 2010, 49 (4), 378-389. https://doi.org/10.1016/j.plipres.2010.05.001.

(4) Heberle, F. A.; Feigenson, G. W. Phase Separation in Lipid Membranes. Cold 
Spring Harb. Perspect. Biol. 2011, 3 (4), a004630.

https://doi.org/10.1101/cshperspect.a004630.

(5) Schmid, F. Physical Mechanisms of Micro- and Nanodomain Formation in

Multicomponent Lipid Membranes. Biochim. Biophys. Acta-Biomembr. 2017, 1859

(4), 509-528. https://doi.org/10.1016/j.bbamem.2016.10.021.

(6) Ingólfsson, H. I.; Melo, M. N.; Van Eerden, F. J.; Arnarez, C.; Lopez, C. A.;

Wassenaar, T. A.; Periole, X.; De Vries, A. H.; Tieleman, D. P.; Marrink, S. J. Lipid

Organization of the Plasma Membrane. J. Am. Chem. Soc. 2014, 136(41), 14554-

14559. https://doi.org/10.1021/ja507832e.

(7) Cebecauer, M.; Amaro, M.; Jurkiewicz, P.; Sarmento, M. J.; Šachl, R.; Cwiklik, L.;

Hof, M. Membrane Lipid Nanodomains. Chem. Rev. 2018, 118(23), 11259-11297.

https://doi.org/10.1021/acs.chemrev.8b00322.

(8) Shaw, A. S. Lipid Rafts: Now You See Them, Now You Don't. Nat. Immunol. 2006, 7(11), 1139-1142. https://doi.org/10.1038/ni1405. 
(9) George, K. S.; Wu, S. Lipid Raft: A Floating Island of Death or Survival. Toxicol. Appl. Pharmacol. 2012, $259 \quad$ (3), 311-319. https://doi.org/10.1016/j.taap.2012.01.007.

(10) Goñi, F. M. "Rafts": A Nickname for Putative Transient Nanodomains. Chem. Phys. Lipids 2019, $218 \quad$ (November 2018), $34-39$. https://doi.org/10.1016/j.chemphyslip.2018.11.006.

(11) Marquardt, D.; Heberle, F. A.; Nickels, J. D.; Pabst, G.; Katsaras, J. On Scattered Waves and Lipid Domains: Detecting Membrane Rafts with X-Rays and Neutrons. Soft Matter 2015, 11 (47), 9055-9072. https://doi.org/10.1039/C5SM01807B.

(12) Kaiser, H. J.; Lingwood, D.; Levental, I.; Sampaio, J. L.; Kalvodova, L.; Rajendran, L.; Simons, K. Order of Lipid Phases in Model and Plasma Membranes. Proc. Natl. Acad. Sci. 2009, 106 (39), 16645. https://doi.org/10.1073/pnas.0908987106.

(13) Strahl, H.; Errington, J. Bacterial Membranes: Structure, Domains, and Function. Annu. Rev. Microbiol. 2017, 71 (1), 519-538. https://doi.org/10.1146/annurevmicro-102215-095630. 
(14) Frolov, V. A.; Shnyrova, A. V.; Zimmerberg, J. Lipid Polymorphisms and Membrane Shape. Cold Spring Harb. Perspect. Biol. 2011, 3 https://doi.org/10.1101/cshperspect.a004747.

(15) McMahon, H. T.; Boucrot, E. Membrane Curvature at a Glance. J. Cell Sci. 2015, 128 (6), 1065-1070. https://doi.org/10.1242/jcs.114454.

(16) Jarsch, I. K.; Daste, F.; Gallop, J. L. Membrane Curvature in Cell Biology: An Integration of Molecular Mechanisms. J. Cell Biol. 2016, 214 (4), 375-387. https://doi.org/10.1083/jcb.201604003.

(17) Bagatolli, L.; Gratton, E.; Khan, T. K.; Chong, P. L. Two-Photon Fluorescence Microscopy Studies of Bipolar Tetraether Giant Liposomes from Thermoacidophilic Archaebacteria Sulfolobus Acidocaldarius. Biophys $J$ 2000, 79 (1), 416-425. https://doi.org/10.1016/S0006-3495(00)76303-X.

(18) De Rosa, M.; Gambacorta, A.; Gliozzi, A. Structure, Biosynthesis, and Physicochemical Properties of Archaebacterial Lipids. Microbiol. Rev. 1986, 50(1), 70-80. 
(19) Gambacorta, A.; Trincone, A.; Nicolaus, B.; Lama, L.; De Rosa, M. Unique Features of Lipids of Archaea. Syst. Appl. Microbiol. 1993, 16 (4), 518-527. https://doi.org/10.1016/S0723-2020(11)80321-8.

(20) De Rosa, M. Archaeal Lipids: Structural Features and Supramolecular Organization. Thin Solid Films 1996, 284-285, 13-17. https://doi.org/10.1016/S0040-6090(96)08832-3.

(21) De Rosa, M.; Gambacorta, A.; Nicolaus, B. A New Type of Cell Membrane, in Thermophilic Archaebacteria, Based on Bipolar Ether Lipids. J. Memb. Sci. 1983, 16 (C), 287-294. https://doi.org/10.1016/S0376-7388(00)81316-2.

(22) Gliozzi, A.; Paoli, G.; De Rosa, M.; Gambacorta, A. Effect of Isoprenoid Cyclization on the Transition Temperature of Lipids in Thermophilic Archaebacteria. Biochim. Biophys. Acta - Biomembr. 1983, 735 (2), 234-242. https://doi.org/10.1016/00052736(83)90298-5.

(23) Gliozzi, A.; Rolandi, R.; De Rosa, M.; Gambacorta, A. Monolayer Black Membranes from Bipolar Lipids of Archaebacteria and Their Temperature-Induced Structural 
Changes. J. Membr. Biol. 1983, $75 \quad$ (1), 45-56.

https://doi.org/10.1007/BF01870798.

(24) Yamauchi, K.; Doi, K.; Yoshida, Y.; Kinoshita, M. Archaebacterial Lipids: Highly

Proton-Impermeable Membranes from 1,2-Diphytanyl-Sn-Glycero-3-

Phosphocoline. Biochim. Biophys. Acta - Biomembr. 1993, 1146 (2), 178-182.

https://doi.org/10.1016/0005-2736(93)90353-2.

(25) Elferink, M. G. L.; de Wit, J. G.; Driessen, A. J. M.; Konings, W. N. Stability and

Proton-Permeability of Liposomes Composed of Archaeal Tetraether Lipids.

Biochim. Biophys. Acta - Biomembr. 1994, 1193 (2), 247-254.

https://doi.org/10.1016/0005-2736(94)90160-0.

(26) Shinoda, W.; Mikami, M.; Baba, T.; Hato, M. Molecular Dynamics Study on the Effects of Chain Branching on the Physical Properties of Lipid Bilayers: 2. Permeability. J. Phys. Chem. B 2004, 108 (26), 9346-9356. https://doi.org/10.1021/jp035998+.

(27) Yamauchi, K.; Doi, K.; Kinoshita, M.; Kii, F.; Fukuda, H. Archaebacterial Lipid 
Models: Highly Salt-Tolerant Membranes from 1,2-Diphytanylglycero-3-

Phosphocholine. Biochim. Biophys. Acta - Biomembr. 1992, 1110 (2), 171-177.

https://doi.org/10.1016/0005-2736(92)90355-P.

(28) Chang, E. L. Unusual Thermal Stability of Liposomes Made from Bipolar Tetraether Lipids. Biochemical and Biophysical Research Communications. 1994, pp 673679. https://doi.org/10.1006/bbrc.1994.1983.

(29) Yasmann, A.; Sukharev, S. Properties of Diphytanoyl Phospholipids at the AirWater Interface. Langmuir 2015, $31 \quad$ (1), 350-357. https://doi.org/10.1021/la503800g.

(30) Van de Vossenberg, J. L. C. M.; Driessen, A. J. M.; Konings, W. N. The Essence of Being Extremophilic: The Role of the Unique Archaeal Membrane Lipids. Extremophiles 1998, 2(3), 163-170. https://doi.org/10.1007/s007920050056.

(31) Takai, K.; Nakamura, K.; Toki, T.; Tsunogai, U.; Miyazaki, M.; Miyazaki, J.; Hirayama, H.; Nakagawa, S.; Nunoura, T.; Horikoshi, K. Cell Proliferation at 122 C and Isotopically Heavy CH4 Production by a Hyperthermophilic Methanogen under 
High-Pressure Cultivation. Proc. Natl. Acad. Sci. 2008, 105 (31), 10949-10954.

https://doi.org/10.1073/pnas.0712334105.

(32) Schleper, C.; Puehler, G.; Holz, I.; Gambacorta, A.; Janekovic, D.; Santarius, U.;

Klenk, H. P.; Zillig, W. Picrophilus Gen. Nov., Fam. Nov.: A Novel Aerobic,

Heterotrophic, Thermoacidophilic Genus and Family Comprising Archaea Capable

of Growth around PH 0. J. Bacteriol. 1995, 177 (24), 7050-7059.

https://doi.org/10.1128/JB.177.24.7050-7059.1995.

(33) Birrien, J. L.; Zeng, X.; Jebbar, M.; Cambon-Bonavita, M. A.; Quérellou, J.; Oger,

P.; Bienvenu, N.; Xiao, X.; Prieur, D. Pyrococcus Yayanosii Sp. Nov., an Obligate

Piezophilic Hyperthermophilic Archaeon Isolated from a Deep-Sea Hydrothermal

Vent. Int. J. Syst. Evol. Microbiol. 2011, 61 (12), 2827-2831.

https://doi.org/10.1099/ijs.0.024653-0.

(34) Hafenbradl, D.; Keller, M.; Stetter, K. O. Lipid Analysis of Methanopyrus Kandleri.

FEMS Microbiol. Lett. 1996, 136 (2), 199-202. https://doi.org/10.1016/0378-

1097(96)84201-7. 
(35) Cario, A.; Grossi, V.; Schaeffer, P.; Oger, P. M. Membrane Homeoviscous Adaptation in the Piezo-Hyperthermophilic Archaeon Thermococcus Barophilus. Front. Microbiol. 2015, 6(OCT), 1-12. https://doi.org/10.3389/fmicb.2015.01152.

(36) Clejan, S.; Krulwich, T. A.; Mondrus, K. R.; Seto-Young, D. Membrane Lipid Composition of Obligately and Facultatively Alkalophilic Strains of Bacillus Spp. J. Bacteriol. 1986, 168 (1), 334-340. https://doi.org/10.1128/jb.168.1.334-340.1986.

(37) Salvador-Castell, M.; Tourte, M.; Oger, P. M. In Search for the Membrane Regulators of Archaea. Int. J. Mol. Sci. 2019, 20 (18), 4434. https://doi.org/10.3390/ijms20184434.

(38) Gilmore, S. F.; Yao, A. I.; Tietel, Z.; Kind, T.; Facciotti, M. T.; Parikh, A. N. Role of Squalene in the Organization of Monolayers Derived from Lipid Extracts of Halobacterium Salinarum. Langmuir 2013, 29 (25), 7922-7930. https://doi.org/10.1021/la401412t.

(39) de Ghellinck, A.; Shen, C.; Fragneto, G.; Klösgen, B. Probing the Position of Resveratrol in Lipid Bilayers: A Neutron Reflectivity Study. Colloids Surfaces B 
Biointerfaces 2015, 134, 65-72. https://doi.org/10.1016/j.colsurfb.2015.06.028.

(40) Ding, L.; Weiss, T. M.; Fragneto, G.; Liu, W.; Yang, L.; Huang, H. W. Distorted Hexagonal Phase Studied by Neutron Diffraction: Lipid Components Demixed in a Bent Monolayer. Langmuir 2005, $21 \quad$ (1), 203-210. https://doi.org/10.1021/la047876u.

(41) Bée, M. Quasielastic Neutron Scattering: Principles and Applications in Solid State Chemistry, Biology and Materials Science; Adam Hilger: Philadelphia, PA, 1988.

(42) Lakey, J. H. Neutrons for Biologists: A Beginner's Guide, or Why You Should Consider Using Neutrons. J. R. Soc. Interface 2009, 6 Supp/ 5 (August), S567-73. https://doi.org/10.1098/rsif.2009.0156.focus.

(43) Dante, S.; Hauss, T.; Dencher, N. A. $\beta$-Amyloid 25 to 35 Is Intercalated in Anionic and Zwitterionic Lipid Membranes to Different Extents. 2002, 83(November), 26102616.

(44) Hauß, T.; Dante, S.; Dencher, N. A.; Haines, T. H. Squalane Is in the Midplane of 
the Lipid Bilayer: Implications for Its Function as a Proton Permeability Barrier.

$\begin{array}{lllll}\text { Biochim. } & \text { Biophys. }\end{array}$

https://doi.org/doi.org/10.1016/S0005-2728(02)00346-8.

(45) Kessner, D.; Kiselev, M. A.; Hauß, T.; Dante, S.; Wartewig, S.; Neubert, R. H. H.

Localisation of Partially Deuterated Cholesterol in Quaternary SC Lipid Model

Membranes: A Neutron Diffraction Study. Eur. Biophys. J. 2008, 37(6), 1051-1057.

https://doi.org/10.1007/s00249-008-0265-4.

(46) Harroun, T. A.; Katsaras, J.; Wassall, S. R. Cholesterol Is Found to Reside in the

Center of a Polyunsaturated Lipid Membrane. Biochemistry 2008, 47 (27), 70907096. https://doi.org/10.1021/bi800123b.

(47) Hauß, T.; Dante, S.; Haines, T. H.; Dencher, N. A. Localization of Coenzyme Q10 in the Center of a Deuterated Lipid Membrane by Neutron Diffraction. Biochim. Biophys. Acta - Bioenerg. 2005, $1710 \quad$ (1), 57-62. https://doi.org/10.1016/j.bbabio.2005.08.007.

(48) Mojumdar, E. H.; Groen, D.; Gooris, G. S.; Barlow, D. J.; Lawrence, M. J.; Deme, 
B.; Bouwstra, J. A. Localization of Cholesterol and Fatty Acid in a Model Lipid

Membrane: A Neutron Diffraction Approach. Biophys. J. 2013, 105 (4), 911-918.

https://doi.org/10.1016/j.bpj.2013.07.003.

(49) Luchini, A.; Delhom, R.; Demé, B.; Laux, V.; Moulin, M.; Haertlein, M.; Pichler, H.;

Strohmeier, G. A.; Wacklin, H.; Fragneto, G. The Impact of Deuteration on Natural and Synthetic Lipids: A Neutron Diffraction Study. Colloids Surfaces B Biointerfaces

2018, 168, 126-133. https://doi.org/10.1016/j.colsurfb.2018.02.009.

(50) Tristram-Nagle, S. A. Preparation of Oriented, Fully Hydrated Lipid Samples for Structure Determination Using X-Ray Scattering. Methods Mol. Biol. 2007, 400(6), 63-75. https://doi.org/10.1385/1-59745-519-9:63.

(51) Cristiglio, V.; Giroud, B.; Didier, L.; Demé, B. D16 Is Back to Business: More Neutrons, More Space, More Fun. Neutron News 2015, 26 (3), 22-24. https://doi.org/10.1080/10448632.2015.1057051.

(52) Richard, D.; Ferrand, M.; Kearley, G. J. Analysis and Visualisation of NeutronScattering Data. J. Neutron Res. 1996, 4 (1-4), 33-39. 
https://doi.org/10.1080/10238169608200065.

(53) OriginPro, Version 2016. OriginLab Corporation, Northampton, MA, USA.

(54) Salvador-Castell, M.; Deme, B.; Peters, J.; Oger, P. Constructing a Comprehensive Model of the Archaeal Membrane ILL 8-02-809. Insitut Laue Langevin 2018. https://doi.org/10.5291/ILL-DATA.8-02-809.

(55) Kucerka, N.; Nieh, M.; Pencer, J.; Sachs, J.; Katsaras, J. What Determines the Thickness of a Biological Membrane. Gen. Physiol. Biophys. 2009, 28 (2), 117125. https://doi.org/10.4149/gpb_2009_02_117.

(56) Katsaras, J. X-Ray Diffraction Studies of Oriented Lipid Bilayers. Biochem. Cell Biol. 1995, 73 (5-6), 209-218. https://doi.org/10.1139/o95-025.

(57) Worcester, D. L.; Franks, N. P. Structural Analysis of Hydrated Egg Lecithin and Cholesterol Bilayers II.Neutron Diffraction. J. Mol. Biol. 1976, 100, 359-378. https://doi.org/doi.org/10.1016/S0022-2836(76)80068-X.

(58) Nagle, J. F.; Tristram-Nagle, S. Structure of Lipid Bilayers. Biochim. Biophys. Acta 
- Rev. Biomembr. 2000, 1469 (3), 159-195. https://doi.org/10.1016/S0304-

4157(00)00016-2.

(59) Turner, D. C.; Gruner, S. M. X-Ray Diffraction Reconstruction of the Inverted Hexagonal (HII) Phase in Lipid-Water Systems. Biochemistry 1992, 31 (5), 13401355. https://doi.org/10.1021/bi00120a009.

(60) McIntosh, T. J.; Simon, S. A.; MacDonald, R. C. The Organization of N-Alkanes in Lipid Bilayers. Biochim. Biophys. Acta - Biomembr. 1980, 597 (3), 445-463. https://doi.org/10.1016/0005-2736(80)90219-9.

(61) Baumgart, T.; Hess, S.; Webb, W. Imaging Coexisting Fluid Domains in Biomembrane Models Coupling Curvature and Line Tension. Nature 2003, 425 (October), 821-824. https://doi.org/doi.org/10.1038/nature02013.

(62) Hsieh, C.-H.; Sue, S.-C.; Lyu, P.-C.; Wu, W. Membrane Packing Geometry of Diphytanoylphosphatidylcholine Is Highly Sensitive to Hydration: Phospholipid Polymorphism Induced by Molecular Rearrangement in the Headgroup Region. 1997, 73 (August), 870-877. https://doi.org/10.1016/S0006-3495(97)78120-7. 
(63) Kara, S.; Babii, O.; Tkachenko, A. N.; Ulrich, A. S.; Afonin, S.; Komarov, I. V.

Diphytanoyl Lipids as Model Systems for Studying Membrane-Active Peptides.

Biochim. Biophys. Acta - Biomembr. 2017, 1859 (10), 1828-1837.

https://doi.org/10.1016/j.bbamem.2017.06.003.

(64) Salvador-Castell, M.; Brooks, N. J.; Peters, J.; Oger, P. Induction of Non-Lamellar

Phases in Archaeal Lipids at High Temperature and High Hydrostatic Pressure by

Apolar Polyisoprenoids. Biochim. Biophys. Acta - Biomembr. 2020, 1862 (2),

183130. https://doi.org/10.1016/j.bbamem.2019.183130.

(65) Tayebi, L.; Ma, Y.; Vashaee, D.; Chen, G.; Sinha, S. K.; Parikh, A. N. Long-Range Interlayer Alignment of Intralayer Domains in Stacked Lipid Bilayers. Nat. Mater. 2012, 11 (12), 1074-1080. https://doi.org/10.1038/nmat3451.

(66) Ursell, T. S.; Klug, W. S.; Phillips, R. Morphology and Interaction between Lipid Domains. Proc. Natl. Acad. Sci. 2009, 106 (32), 13301-13306. https://doi.org/10.1073/pnas.0903825106.

(67) Sun, W. J.; Tristram-Nagle, S.; Suter, R. M.; Nagle, J. F. Structure of the Ripple 
Phase in Lecithin Bilayers. Proc. Natl. Acad. Sci. U. S. A. 1996, 93 (14), 7008-

7012. https://doi.org/10.1073/pnas.93.14.7008.

(68) Katsaras, J.; Tristram-Nagle, S.; Liu, Y.; Headrick, R. L.; Fontes, E.; Mason, P. C.;

Nagle, J. F. Clarification of the Ripple Phase of Lecithin Bilayers Using Fully

Hydrated, Aligned Samples. Phys. Rev. E 2000, 61 (5), 5668-5677.

https://doi.org/10.1103/PhysRevE.61.5668.

(69) Sengupta, K.; Raghunathan, V. A.; Katsaras, J. Structure of the Ripple Phase of

Phospholipid Multibilayers. Phys. Rev. E - Stat. Physics, Plasmas, Fluids, Relat.

Interdiscip. Top. 2003, 68(3), 12. https://doi.org/10.1103/PhysRevE.68.031710.

(70) Lenz, O.; Schmid, F. Structure of Symmetric and Asymmetric "Ripple" Phases in

Lipid Bilayers. Phys. Rev. Lett. 2007, 98

https://doi.org/10.1103/PhysRevLett.98.058104.

(71) Israelachvili, J. N.; Mitchell, D. J.; Ninham, B. W. Theory of Self-Assembly of Hydrocarbon Amphiphiles into Micelles and Bilayers. J. Chem. Soc. Faraday Trans.

21976, 72, 1525. https://doi.org/10.1039/f29767201525. 
(72) Klacsová, M.; Bóta, A.; Balgavý, P. DOPC-DOPE Composition Dependent La-HII Thermotropic Phase Transition: SAXD Study. Chem. Phys. Lipids 2016, 198, 4650. https://doi.org/10.1016/j.chemphyslip.2016.05.004.

(73) Lenne, P. F.; Nicolas, A. Physics Puzzles on Membrane Domains Posed by Cell Biology. Soft Matter 2009, 5(15), 2841-2848. https://doi.org/10.1039/b822956b.

(74) Risselada, H. J. Membrane Fusion Stalks and Lipid Rafts: A Love-Hate Relationship. Biophys. J. 2017, $112 \quad$ (12), 2475-2478. https://doi.org/10.1016/j.bpj.2017.04.031. 


\section{Table of content (TOC)}

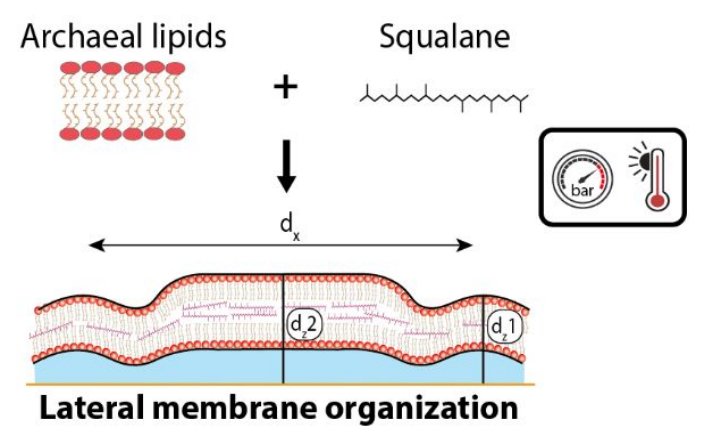

Schematic representation of DoPhPC:DoPhPE (9:1) + $10 \mathrm{~mol} \%$ squalane at $328 \mathrm{~K}$. 